\title{
Surveying techniques in vibration measurement
}

\author{
Przemyslaw Kuras ${ }^{1, a}$ \\ ${ }^{1}$ AGH University of Science and Technology, Department of Engineering Surveying and Civil Engineering, 30 Mickiewicza Av., 30-059 \\ Krakow, Poland
}

\begin{abstract}
In order to determine the actual dynamic characteristics of engineering structures, it is necessary to perform direct measurements. The paper focuses on the problem of using various devices to measure vibration, with particular emphasis on surveying instruments. The main tool used in this study is the radar interferometer, which has been compared to: robotic total station, GNSS receivers and sensors (accelerometer and encoder). The results of four dynamic experiments are presented. They were performed on: industrial chimney, drilling tower, railway bridge and pedestrian footbridge. The obtained results have been discussed in terms of the requirements imposed by the standard ISO 4866:2010.
\end{abstract}

\section{Introduction}

Determination of the actual parameters, which characterize the dynamics of building structures, requires a direct measurement. In practice the design assisted by testing is of particular importance. The standard EN 1990:2002 [1] specifies the circumstances in which it may be necessary to carry out direct measurement. They are:

- the inability to apply the adequate calculation models,

- the need for a large number of similar components,

- the need to confirm the design assumptions.

Mechanical vibration can be characterized by the changes of physical quantities such as displacement, velocity and acceleration. With the knowledge of transfer function of the sensing system, each of them can be calculated on the basis of another by integration or differentiation. However, the standard ISO 4866:2010 [2] recommends avoiding these computational processes and recommends the direct measurement of the required quantity.

The actual values of dynamic characteristics can be determined on the basis of measurement of displacement, velocity or acceleration, performed in proper points representing the tested structure.

The frequency range of structure vibration depends on the spectral content of the forcing and the mechanical response of the structure. It is assumed [2] that the range from $0.1 \mathrm{~Hz}$ to $500 \mathrm{~Hz}$ covers a large variety of excitation sources, both natural (such as wind) and artificial (such as impacts during operation). Measurement of vibration deriving from machinery may, however, require a much wider frequency range, while for measuring vibration of tall structures and bridges the sampling frequency can be reduced. In addition, the structure frequency response to wind excitation, is defined in the range of $0.1 \div 10 \mathrm{~Hz}$.

\footnotetext{
${ }^{\mathrm{a}}$ Corresponding author: kuras@agh.edu.pl
}

The most important requirements for vibration measurement contained in the standard ISO 4866:2010, which are particularly important from the point of view of this study, are as follows:

- measuring the amplitude should be carried out in the continuous manner, with sufficient accuracy and long enough to separate the spectral content,

- the sampling frequency should be at least five times greater than the highest frequency of the analyzed vibration,

- the measuring system should allow to estimate the frequency of vibration with the error of $\pm 0.5 \%$, and the damping with the error of $\pm 20 \%$.

\section{Instrumentation}

\subsection{Ground-based interferometric radar}

The ground-based radar interferometry (GB-SAR) technique is used to measure both static and dynamic displacements of structures that reflect and scatter the radar beam. An example of device used for measuring vibration of engineering structures, in particular of elongated shape, is the radar IBIS-S (Figs. 1, 6, 7). This system has been being developed for about 15 years. The displacements are observed as phase differences of waves $(\lambda=17.4 \mathrm{~mm})$, transmitted by radar and reflected by the structure [3-6].

A lot of points on the structure can be observed simultaneously by the device, thanks to the applied wave modulation [7]. Range resolution, which is the minimum distance between the separately observed points, reaches $0.5 \mathrm{~m}$. Sampling rate is up to $200 \mathrm{~Hz}$, and the range of operation - up to $1 \mathrm{~km}$. However, these parameters are interdependent. Displacement measurement error is 0.1 
$\mathrm{mm}$, provided properly strong wave reflections. Observations can be performed without access to the structure. An important limitation is the ability to measure displacement in only one direction - along the radar axis. Moreover, it may be problematic (especially when compared with measurements using sensors and surveying instruments) to pinpoint the location of an observed point. It is limited to the value of the range resolution $(0.5 \mathrm{~m}-$ in the best case). Nevertheless, a clear identification of the observed point can be achieved by installing radar reflectors on the structure but it means the need for direct access to the structure.

\subsection{Robotic total station}

Total station (Fig. 1) is a standard instrument used in engineering surveying to determine long-term displacements by measuring angles and distances to prisms set on the observed points. However, the dynamic displacements measurements using these instruments are also possible thanks to the systems which have been developed over the last 20 years. The most important are: the use of servomotors, which allows the automatic rotation of the instrument, and tracking a moving prism. In this way, observations of changes in direction and distance allow to determine the spatial movements of the prism [8]. Currently the fastest measurement instruments can achieve the frequency of $10 \mathrm{~Hz}$. The position is determined with an accuracy of $1 \div 2 \mathrm{~mm}$, but the precision of displacement measurement is often higher.

Another way is the observation of changes of one quantity. This solution may result in higher frequency measurement. Tracking the horizontal direction can determine the displacements perpendicular to the axis of the instrument, while the distance observation - the radial values, along the line of sight. Distance measurement can be carried out in reflectorless mode (without the use of prism), but it decreases the measurement accuracy.

\subsection{GNSS receiver}

Another surveying solution for vibration measurement is the use of precise dual-frequency GNSS (Global Navigation Satellite System) receivers. Position of the antenna, which is mounted on the structure (Fig. 7), is determined with a frequency of about $20 \mathrm{~Hz}$ or even 100 $\mathrm{Hz}$ - using special receivers. In order to achieve the most accurate results, two receivers, first on a vibrating structure and second in its vicinity (in the distance of 100 $\mathrm{m})$, operating in differential mode, should be used [9]. This technique ensures the accuracy of $10 \mathrm{~mm}+1$ $\mathrm{mm} / \mathrm{km}$ (for horizontal position) and $20 \mathrm{~mm}+1 \mathrm{~mm} / \mathrm{km}$ (for vertical position).

In the case of GNSS surveying it is essential to ensure the horizon visibility, which allows to receive correct signals from satellites. In the case of engineering structures there are significant limitations of antennas mounting. The field conditions must be considered when planning observations in order to avoid the problems with obstacles in the horizon and satellite signals multipath. In some cases, the advanced equipment for attenuating the reflected signals (e.g. choke-ring antennas) may be necessary.

\subsection{Sensors}

The most common way to measure vibration is the use of electrical sensors, which convert mechanical quantities to electrical ones. Depending on the measured physical quantity, displacement, velocity and acceleration sensors are distinguished. Choosing the right sensor depends on the expected vibration frequency of the structure. As a general rule it is assumed that for low frequencies (from 0 to $10 \mathrm{~Hz}$ ) displacement sensors are used, in the medium range (below $1 \mathrm{kHz}$ ) - velocity sensors, and for measuring the movement of the higher frequencies accelerometers [10].

There are a variety of sensors dedicated to different applications. The most common type of sensors are accelerometers, especially piezoelectric, which can be applied to vibration monitoring $[11,12]$. Due to the range of amplitudes and frequencies they are the most versatile and reliable. The advantages of piezoelectric accelerometers include high measurement resolution, low noise and a wide frequency range. The disadvantages are, however, temperature drift and the need for frequent calibration. Accelerometers work in a broad frequency range from fractions of a hertz to about $20 \mathrm{kHz}$.

Recently another type of accelerometers, microelectro-mechanical systems, is widely used [13]. MEMS sensors have the ability to measure the static acceleration, and they are characterized by low temperature drift, no need for frequent calibrated and a relatively low price. In comparison with the piezoelectric sensors MEMS accelerometers have lower resolution, narrower frequency band and higher noise level.

Apart from accelerometers, different types of sensors are used for vibration measurements [10]. This paper point out the sensor, which uses an incremental optical encoder for direct displacement measurement. The encoder consists of precise measuring ring with the pattern of 20-micrometer bands and a readhead recording their location. Vertical movement is transmitted to the device using a steel string hooked on the tested structure in particular place, and results as rotation of the measuring ring (Fig. 6). The lower end of the string is loaded to ensure its verticality. The logging rate of signals from the readhead is $1000 \mathrm{~Hz}$, so that the apparatus is suitable for measurement of vibration.

\section{Tall structures}

Vibrations caused by frequently occurring factor - wind excitation is presented in the paper. The tests were performed on two structures (Fig. 1): industrial steel chimney (height: $60 \mathrm{~m}$ ) and drilling tower (height: $30 \mathrm{~m}$ ).

\subsection{Industrial steel chimney}

A few samples of chimney vibration measurement, performed in order to tune the damper installed on the top of the chimney, are presented in the paper. The 
observations were acquired in three damper setups: 1) inactive - in order to determine the actual vibration frequency, 2) initially tuned - based on the preliminary calculations, 3) ultimately tuned - based on the measurement [14]. The damper is used to reduce the impact of wind excitation.
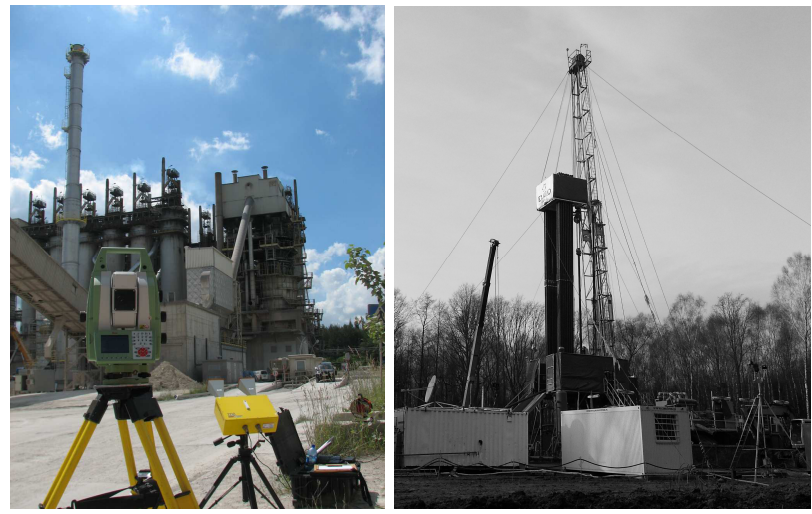

Figure 1. The examined tall structures: industrial steel chimney observed by robotic total station and interferometric radar (left), drilling tower (right).

Vibration measurements were carried out using ground-based radar interferometer and robotic total station. The sampling frequency of radar was $165 \mathrm{~Hz}$, and total station $-5.5 \mathrm{~Hz}$. The $\mathrm{X}$ axis was assumed as the direction between instrument and the top of the chimney, while the $\mathrm{Y}$ axis - perpendicularly. The measurement result of vibrations caused by one of the excitations is presented in Fig. 2.
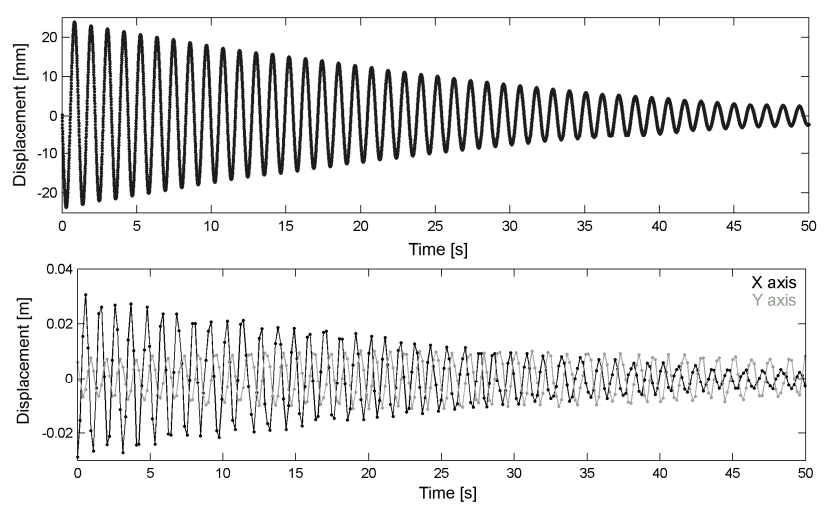

Figure 2. Displacement recorded by the radar (top) and total station (bottom).

In order to verify the effectiveness of the damper some dynamic characteristics (vibration frequency $f$ and logarithmic decrement of damping $\Lambda$ ) were calculated for each excitation, together with their errors, and summarized in Tabs. 1, 2.

A very high reproducibility of the radar observations results can be noticed. The conditions referring to errors of frequency and logarithmic decrement of damping, required by the standard ISO $4866: 2010(0.5 \%$ and $20 \%$, respectively), are highly satisfied. In the case of total station the values of $\sigma_{f}$ and $\sigma_{A}$ exceed the limit values in some cases, especially for a strong damping caused by the ultimately tuned damper. However, total station, in contrast to radar, allow the observation of spatial displacements.

Table 1. Vibration frequency of the chimney.

\begin{tabular}{|c|c|c|c|c|c|}
\hline \multirow{2}{*}{$\begin{array}{c}\text { Damper } \\
\text { setup }\end{array}$} & \multirow{2}{*}{ Axis } & \multicolumn{2}{|c|}{ Radar } & \multicolumn{2}{c|}{ Total station } \\
\cline { 3 - 6 } & & $f[\mathrm{~Hz}]$ & $\sigma_{f}[\%]$ & $f[\mathrm{~Hz}]$ & $\sigma_{f}[\%]$ \\
\hline \multirow{4}{*}{ Inactive } & \multirow{3}{*}{$\mathrm{X}$} & 0.905 & 0.01 & 0.920 & 0.21 \\
& & 0.905 & 0.01 & 0.904 & 0.04 \\
& & - & - & 0.897 & 0.25 \\
& \multirow{2}{*}{$\mathrm{Y}$} & - & - & 0.904 & 0.07 \\
& & - & - & 0.888 & 0.14 \\
\hline Initially & $\mathrm{X}$ & 0.926 & 0.01 & 0.935 & 0.29 \\
\cline { 2 - 6 } tuned & $\mathrm{Y}$ & - & - & 0.900 & 0.71 \\
\hline & & 0.921 & 0.03 & 0.862 & 0.22 \\
& $\mathrm{X}$ & 0.922 & 0.03 & 0.918 & 0.73 \\
Ultimate- & & 0.923 & 0.02 & 0.916 & 0.59 \\
\cline { 2 - 6 } ly tuned & \multirow{3}{*}{} & - & - & 0.904 & 0.84 \\
& $\mathrm{Y}$ & - & - & 0.898 & 0.28 \\
& & - & - & 0.863 & 0.76 \\
\hline
\end{tabular}

Table 2. Damping decrement of the chimney.

\begin{tabular}{|c|c|c|c|c|c|}
\hline \multirow{2}{*}{$\begin{array}{c}\text { Damper } \\
\text { setup }\end{array}$} & \multirow{2}{*}{ Axis } & \multicolumn{2}{|c|}{ Radar } & \multicolumn{2}{|c|}{ Total station } \\
\hline & & $\Lambda[\mathrm{Hz}]$ & $\sigma_{\Lambda}[\%]$ & $\Lambda[\mathrm{Hz}]$ & $\sigma_{\Lambda}[\%]$ \\
\hline \multirow{6}{*}{ Inactive } & & 0.044 & 0.3 & 0.065 & 19 \\
\hline & $\mathrm{X}$ & 0.035 & 0.3 & 0.043 & 5 \\
\hline & & 0.034 & 0.4 & 0.047 & 16 \\
\hline & & - & - & 0.094 & 16 \\
\hline & Y & - & - & 0.059 & 7 \\
\hline & & - & - & 0.062 & 13 \\
\hline \multirow{2}{*}{$\begin{array}{c}\text { Initially } \\
\text { tuned }\end{array}$} & $\mathrm{X}$ & 0.13 & 0.2 & 0.13 & 14 \\
\hline & $\mathrm{Y}$ & - & - & 0.21 & 20 \\
\hline \multirow{6}{*}{$\begin{array}{l}\text { Ultimate- } \\
\text { ly tuned }\end{array}$} & & 0.23 & 0.6 & 0.20 & 7 \\
\hline & $\mathrm{X}$ & 0.23 & 0.8 & 0.24 & 18 \\
\hline & & 0.21 & 0.4 & 0.20 & 18 \\
\hline & & - & - & 0.20 & 25 \\
\hline & Y & - & - & 0.21 & 8 \\
\hline & & - & - & 0.27 & 17 \\
\hline
\end{tabular}

\subsection{Drilling tower}

Another test was performed in order to determine the vibration frequencies of a drilling tower. Vibrations were measured with the use of radar interferometer and a MEMS accelerometer, installed in the middle of the structure. The measurements were conducted for the free vibration of the tower which was not subjected to operational loads. Figs. 3-4 show the results of spectral analysis performed for the 60 -second time period of simultaneous operation of both devices. Two points (Rbin126 and Rbin140) were observed by the radar - on the top and in the middle of the tower.

Although different physical quantities (displacement and acceleration) were subjected to measure, the compatibility of vibration frequency is very high. Both systems allowed the determination of the following frequencies: $0.783 \mathrm{~Hz}, 12.2 \mathrm{~Hz}, 12.8 \mathrm{~Hz}$ and $51.2 \mathrm{~Hz}$, albeit with strongly different amplitude spectrum distribution. More advanced analysis (e.g. filters, window functions) would probably indicate another frequencies, e.g. approx. $10 \mathrm{~Hz}$. 

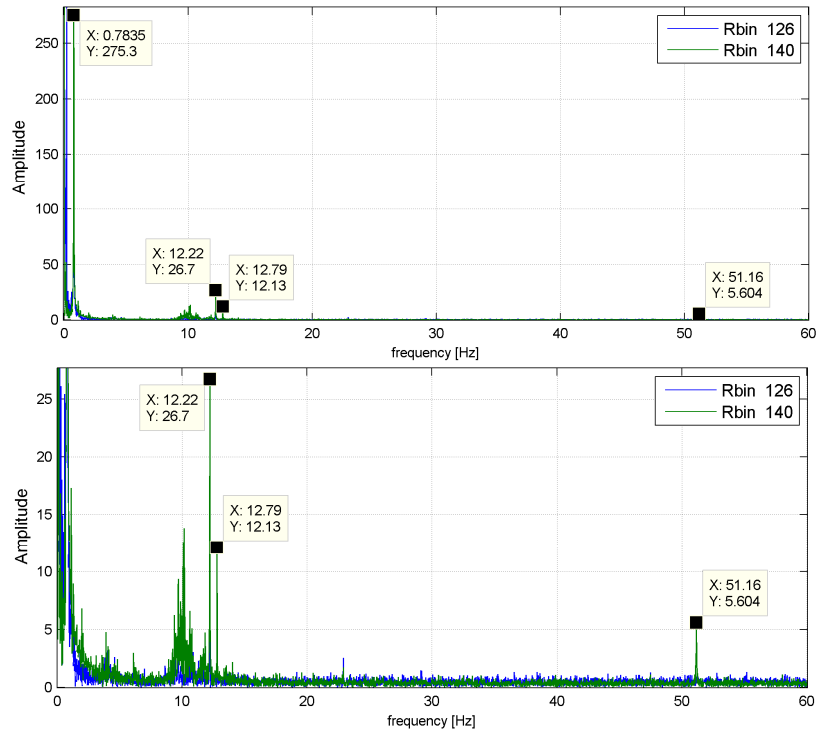

Figure 3. FFT for radar data: full amplitude range (top) and magnification of the low peaks (bottom).
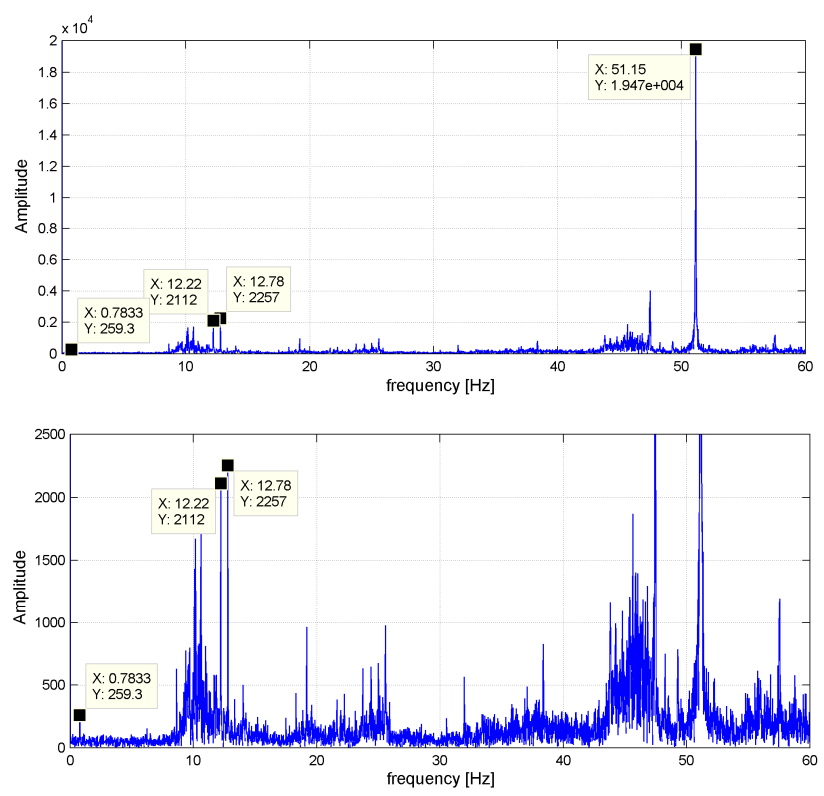

Figure 4. FFT for accelerometer observations: full amplitude range (top) and magnification of the low peaks (bottom).

\section{Bridge structures}

\subsection{Railway steel bridge}

The first test for bridge structure was carried out using the interferometric radar and sensor based on the incremental optical encoder. The aim of the work was to determine the value and the changes of deflection of a steel span of the railway bridge in its central part (Fig. 6), caused by the passing trains. The sampling frequency was: $50 \mathrm{~Hz}$ for the radar and approx. $1000 \mathrm{~Hz}$ for the sensor. The string that caused the change of the encoder reading was attached to the span and loaded with a mass.

In Fig. 5 (top) the result of observation is presented as a graph of raw data from the two instruments, together with the values of differences between deflections. The initial deflection with the value of approx. $14 \mathrm{~mm}$ is the result of heavy locomotive passing, while another $(3 \div 4$ $\mathrm{mm})$ are caused by the empty cargo wagons. On the differences graph a periodic variation is visible. It may be caused by the vibration of measurement system itself (probably the string). To eliminate this factor, a low-pass filter was applied (Fig. 5, bottom). Consequently, the compatibility between the results is better, but this tool should be used with caution because of the risk of removing the impact of significant phenomena from the observations.

Consistency of results obtained using radar and sensor is confirmed by the parameters calculated for differences: - standard deviation: $0.33 \mathrm{~mm}$ and $0.15 \mathrm{~mm}$ (before and after filtration),

- average absolute deviation: $0.24 \mathrm{~mm}$ and $0.12 \mathrm{~mm}$ (before and after filtration).
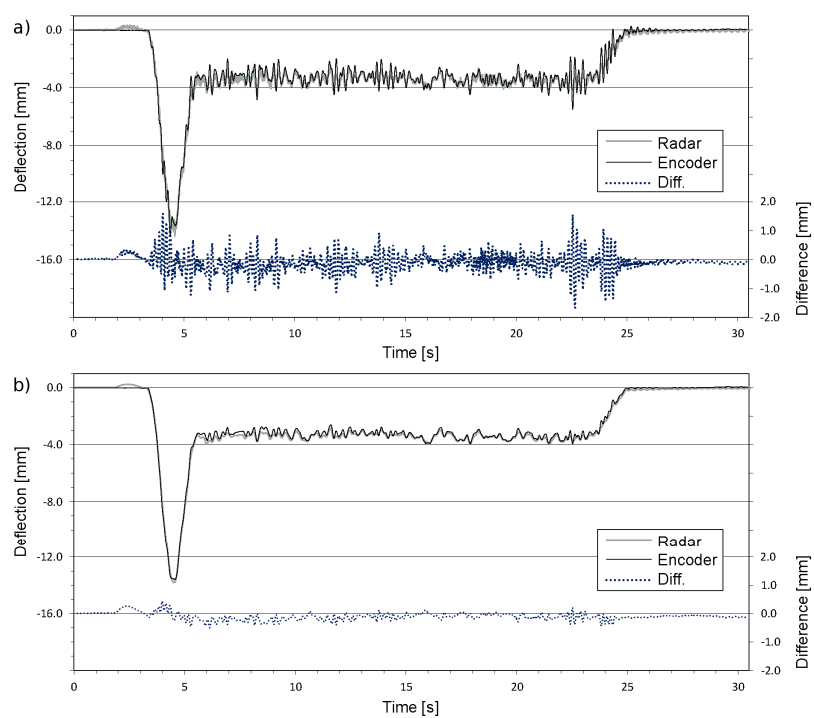

Figure 5. Bridge span deflection before (top) and after (bottom) using the low-pass filter.
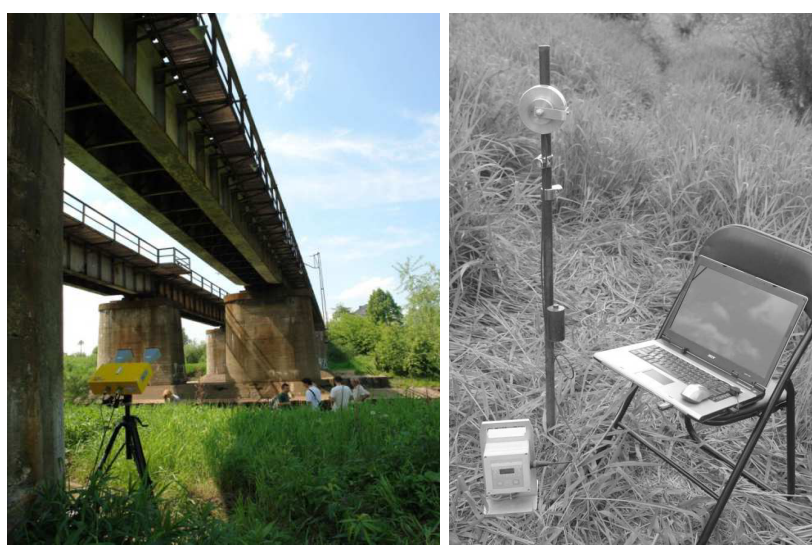

Figure 6. Devices used for bridge deflection measurement: interferometric radar (left) and sensor with optical encoder (right) [15].

\subsection{Footbridge}

The last structure tested for the possibility of using surveying techniques, was a footbridge. The selected 
structure with a length of $70 \mathrm{~m}$ has a large amplitude vibrations. This movement can be determined using satellite technique, which allows to detect displacements larger than several millimeters.

The GNSS antenna was fixed in the middle of the bridge, vertically above the radar reflector. The sampling frequency of the radar was $100 \mathrm{~Hz}$, and the GNSS receiver $-20 \mathrm{~Hz}$. The analysis was carried for the interval $330.0 \div 374.7 \mathrm{~s}$, when the vibrations were induced. Further observations were excluded from the calculations because of the GNSS signal disturbance by a pedestrian. The consistency between results is relatively small, but it results from the low accuracy of satellite measurements. The parameters calculated for the differences are as follows:

- standard deviation: $9.9 \mathrm{~mm}$,

- average absolute deviation: $8.0 \mathrm{~mm}$.

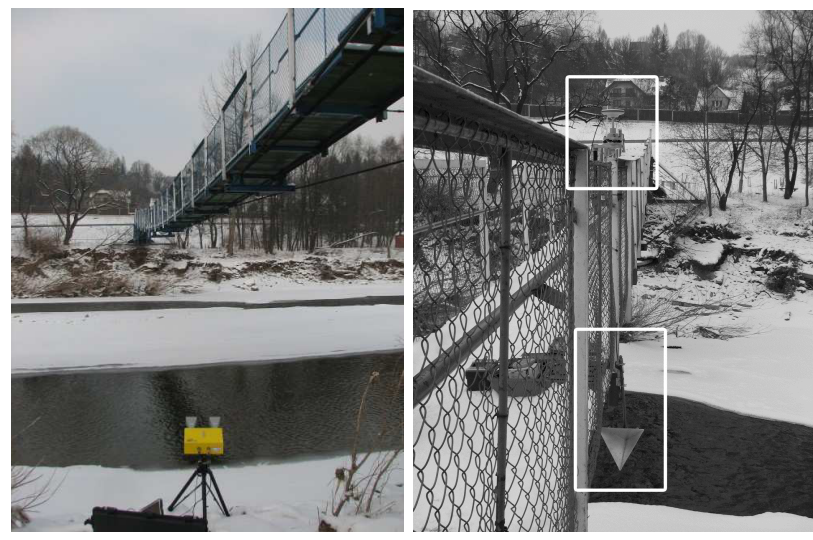

Figure 7. Devices used for footbridge vibration measurement: interferometric radar (left), radar reflector (right, bottom), and GNSS antenna (right, top).

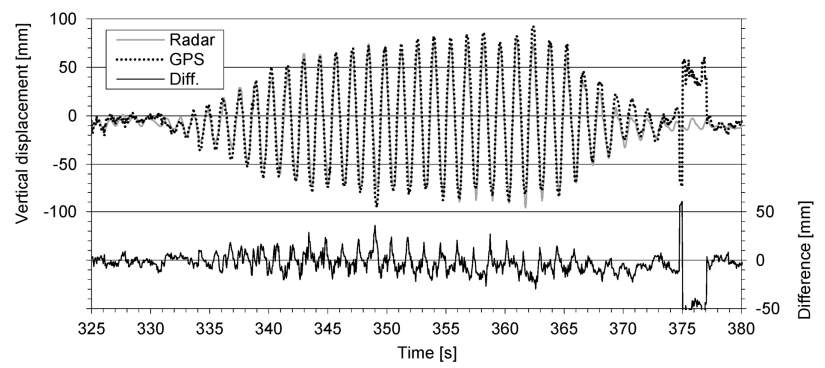

Figure 8. Footbridge vibration recorded by the interferometric radar and GNSS receiver.

\section{Conclusions}

To conduct vibration measurements different instruments and devices with various parameters can be used. An attempt of their comparison is made in Tab. 3. It is not possible to identify clearly the optimal method of measurement due to different field conditions and various needs. The studies have confirmed the limitations of measurement methods, but also indicated a mutual opportunity to expand the observation data.
Table 3. A comparison of the features of measurement devices.

\begin{tabular}{|c|c|c|c|c|c|}
\hline Device & $\begin{array}{l}\text { Inter- } \\
\text { fero- } \\
\text { metric } \\
\text { radar }\end{array}$ & $\begin{array}{l}\text { Total } \\
\text { sta- } \\
\text { tion }\end{array}$ & $\begin{array}{l}\text { GNSS } \\
\text { rece- } \\
\text { iver }\end{array}$ & $\begin{array}{l}\text { Acce- } \\
\text { lero- } \\
\text { meter }\end{array}$ & $\begin{array}{l}\text { Opti- } \\
\text { cal } \\
\text { enco- } \\
\text { der }\end{array}$ \\
\hline $\begin{array}{l}\text { Displacement: } \\
\text { 3D }(+) / 1 \mathrm{D}(-)\end{array}$ & - & $+1-$ & + & $+1-$ & - \\
\hline $\begin{array}{l}\text { Access: non- } \\
\text { contact }(+) / \\
\text { direct }(-)\end{array}$ & $+1-$ & $+1-$ & - & - & - \\
\hline $\begin{array}{c}\text { Maximum } \\
\text { sampling rate } \\
{[\mathrm{Hz}]}\end{array}$ & 200 & 10 & $\begin{array}{l}20 / \\
100\end{array}$ & $\begin{array}{c}0.1 \div \\
20000\end{array}$ & $\begin{array}{l}\text { e.g. } \\
1000\end{array}$ \\
\hline $\begin{array}{c}\text { Displacement } \\
\text { error [mm] }\end{array}$ & 0.1 & $\begin{array}{l}\sim 0.5 \\
\div 2 \\
\end{array}$ & $\begin{array}{c}10 \\
\div 20 \\
\end{array}$ & $\mathrm{n} / \mathrm{a}$ & $\sim 0.1$ \\
\hline $\begin{array}{l}\text { Points observed } \\
\text { by one device }\end{array}$ & $\begin{array}{l}1 \div \text { se- } \\
\text { veral }\end{array}$ & 1 & 1 & 1 & 1 \\
\hline
\end{tabular}

\section{Acknowledgements}

The study was the carried out with financial support from grant no. 15.11.150.242/15, AGH University of Science and Technology.

\section{References}

1. EN 1990:2002, Eurocode - Basis of structural design (2002)

2. ISO 4866:2010, Mechanical vibration and shockVibration of fixed structures - Guidelines for the measurement of vibrations and evaluation of their effects on structures (2010)

3. M. Fratini, M. Pieraccini, D. Dei, F. Parrini, G. Bartoli, C. Atzeni, An experimental comparison of interferometric radar vs. accelerometers for monitoring of large structures (Proc. European Radar Conference EuRAD, 2007)

4. V. Gikas, Journal of Applied Geodesy 6, 3-4 (2012)

5. J. Gocal, Ł. Ortyl, T. Owerko, P. Kuras, R. Kocierz, P. Ćwiąkała, E. Puniach, O. Sukta, A. Bałut, Determination of displacement and vibrations of engineering structures using ground-based radar interferometry (AGH University of Science and Technology Press, 2013)

6. F. Neitzel, W. Niemeier, S. Weisbrich, M. Lehmann, Investigation of low-cost accelerometer, terrestrial laser scanner and ground-based radar interferometer for vibration monitoring of bridges (Proc. $6^{\text {th }}$ European Workshop on Structural Health Monitoring, 2012)

7. M. Pieraccini, The Scientific World Journal 2013 (2013)

8. P. Psimoulis, S. Stiros, J. Bridge Eng. 18, 2 (2013)

9. X. Meng, A.H. Dodson, G.W. Roberts, Eng. Struct. 29, 11 (2007)

10. J. Fraden, Handbook of Modern Sensors: Physics, Designs, and Applications (Springer, 2010)

11. A. Kopáčik, I. Lipták, P. Kyrinovič, J. Erdélyi, Monitoring of a cycling bridge using accelerometers and ground-based radar - a case study (Proc. $2^{\text {nd }}$ Joint International Symposium on Deformation Monitoring, 2013) 
12. V. Lekidis, M. Tsakiri, K. Makra, C. Karakostas, N. Klimis, I. Sous, Eng. Geol. 79 (2005)

13. A. Albarbar, S. Mekid, A. Starr, R. Pietruszkiewicz, Sensors 8 (2008)

14. P. Kuras, Ł. Ortyl, M. Kędzierski, P. Podstolak, Measurement Automation and Monitoring 60, 12 (2014)

15. M. Jamka, P. Kuras, M. Strach, Przegląd Komunikacyjny (in Polish) 9-10 (2011) 